\title{
Promoting positive maternal, newborn, and child health behaviors through a group- based health education and microfinance program: a prospective matched cohort study in western Kenya
}

\author{
Lauren Y. Maldonado ${ }^{1,2^{*}}$ (D, Julia J. Songok ${ }^{1,3}$, John W. Snelgrove ${ }^{4}$, Christian B. Ochieng ${ }^{5}$, Sheilah Chelagat ${ }^{1}$,
} Justus E. Ikemeri ${ }^{1}$, Monica A. Okwanyi ${ }^{6}$, Donald C. Cole ${ }^{7}$, Laura J. Ruhl ${ }^{1,3,8+}$ and Astrid Christoffersen-Deb ${ }^{1,3,9+}$

\begin{abstract}
Background: Chamas for Change (Chamas) is a group-based health education and microfinance program for pregnant and postpartum women that aims to address inequities contributing to high rates of maternal and infant mortality in rural western Kenya. In this prospective matched cohort study, we evaluated the association between Chamas participation and facility-based delivery. We additionally explored the effect of participation on promoting other positive maternal, newborn and child health (MNCH) behaviors.

Methods: We prospectively compared outcomes between a cohort of Chamas participants and controls matched for age, parity, and prenatal care location. Between October-December 2012, government-sponsored community health volunteers (CHV) recruited pregnant women attending their first antenatal care (ANC) visits at rural health facilities in Busia County to participate in Chamas. Women enrolled in Chamas agreed to attend group-based health education and microfinance sessions for one year; controls received the standard of care. We used descriptive analyses, multivariable logistic regression models, and random effect models to compare outcomes across cohorts 12 months following enrollment, with a set to 0.05 .

\footnotetext{
* Correspondence: lymaldon@gmail.com

${ }^{\dagger}$ Laura J. Ruhl and Astrid Christoffersen-Deb contributed equally to this work

${ }^{1}$ Academic Model Providing Access to Healthcare (AMPATH), P.O. Box 4606, Eldoret 30100, Kenya

²Department of Medicine, Department of Pediatrics, Massachusetts General Hospital, Boston, MA, USA

Full list of author information is available at the end of the article
}

(c) The Author(s). 2020 Open Access This article is licensed under a Creative Commons Attribution 4.0 International License, which permits use, sharing, adaptation, distribution and reproduction in any medium or format, as long as you give appropriate credit to the original author(s) and the source, provide a link to the Creative Commons licence, and indicate if changes were made. The images or other third party material in this article are included in the article's Creative Commons licence, unless indicated otherwise in a credit line to the material. If material is not included in the article's Creative Commons licence and your intended use is not permitted by statutory regulation or exceeds the permitted use, you will need to obtain permission directly from the copyright holder. To view a copy of this licence, visit http://creativecommons.org/licenses/by/4.0/ The Creative Commons Public Domain Dedication waiver (http://creativecommons.org/publicdomain/zero/1.0/) applies to the data made available in this article, unless otherwise stated in a credit line to the data. 
(Continued from previous page)

Results: Compared to controls $(n=115)$, a significantly higher proportion of Chamas participants $(n=211)$ delivered in a health facility $(84.4 \%$ vs. 50.4\%, $p<0.001)$, attended at least four ANC visits (64.0\% vs. 37.4\%, $p<0.001)$, exclusively breastfed to six months ( $82.0 \%$ vs. 47.0\%, p <0.001), and received a CHV home visit within $48 \mathrm{~h}$ postpartum (75.8\% vs. 38.3\%, p < 0.001). In multivariable models, Chamas participants were over five times as likely as controls to deliver in a health facility (OR 5.49, 95\% Cl 3.12-9.64, $p<0.001)$. Though not significant, Chamas participants experienced a lower proportion of stillbirths (0.9\% vs. 5.2\%), miscarriages (5.2\% vs. $7.8 \%)$, infant deaths (2.8\% vs. 3.4\%), and maternal deaths (0.9\% vs. $1.7 \%)$ compared to controls.

Conclusions: Chamas participation was associated with increased odds of facility-based delivery compared to the standard of care in rural western Kenya. Larger proportions of program participants also practiced other positive MNCH behaviors. Our findings demonstrate Chamas' potential to achieve population-level MNCH benefits; however, a larger study is needed to validate this observed effect.

Trial registration: ClinicalTrials.gov, NCT03188250 (retrospectively registered 31 May 2017).

Keywords: Pregnancy, Community health volunteer, Maternal health, Newborn or infant health, Peer support, Health education, Microfinance, Financial inclusion, Low- and middle-income country (LMIC), Kenya

\section{Background}

Addressing preventable maternal and infant deaths is a significant challenge on the global agenda. As part of Sustainable Development Goal (SDG) 3, the World Health Organization (WHO) and United Nations tasked countries with reducing their maternal mortality ratio (MMR) to less than 70 maternal deaths per 100,000 livebirths and neonatal mortality rate (NMR) to less than 12 deaths per 1000 livebirths by 2030 [1]. This is an ambitious target for Kenya, where the MMR and NMR are 362 per 100,000 and 22 per 1000 livebirths, respectively [2]. Evidencebased strategies that enhance the practice of lifesaving Maternal, Newborn and Child Health $(\mathrm{MNCH})$ behaviors are urgently needed to meet these SDG targets [3, 4].

Per WHO and Republic of Kenya Ministry of Health $(\mathrm{MOH})$ recommendations, these health behaviors may include: delivering in health facilities with skilled birth attendants (SBA), attending at least four focused antenatal care (ANC) visits, receiving a community health volunteer (CHV) home visit within $48 \mathrm{~h}$ of delivery, and exclusively breastfeeding (EBF) infants to six months [5-11]. Promoting access to and increasing use of long-term family planning (FP) methods may decrease risk for maternal and perinatal morbidity and mortality by allowing women to limit and space pregnancies [12-14]. Further, ensuring infants receive the Oral Polio Vaccination at birth (OPV0) may increase protection against infectious disease mortality during the first year of life [15].

In rural Kenya, only half of women deliver in a health facility with an SBA (47\%), attend at least four ANC visits (51.3\%), and receive a CHV visit within the first 48 $\mathrm{h}$ after delivery (53\%) [2]. EBF beyond the initial months postpartum is uncommon, lasting a median of 3.4 months among rural populations [16]. Less than half of all women currently use a modern FP method (39.1\%), and among users, less than $10 \%$ select a long-term or permanent method [2]. From an equity perspective, poor $\mathrm{MNCH}$ outcomes are disproportionate across socioeconomic strata. Access to care is generally correlated with economic accessibility and women of lower socioeconomic status often encounter greater barriers to accessing high quality care $[2,17]$.

In addition to promoting positive $\mathrm{MNCH}$ behaviors, one of the key enablers in meeting the SDGs is financial inclusion. The World Bank defines financial inclusion for individuals as "access to useful and affordable financial products and services that meet their needs - transactions, payments, savings, credit and insurance - delivered in a responsible and sustainable way." [18] The ability to store money, transfer payments and access loans is increasingly recognized as a vital strategy to overcome financial barriers to health. In Kenya, however, it is estimated that up to one-third of the population is excluded from the formal financial sector [19]. This is particularly true among women in rural Kenya, who are disproportionately excluded from participating in formal income generating activities, making it difficult to adequately finance health-related expenditures [19]. This continued pattern of exclusion of poor and rural women perpetuates their precarious financial and social position.

To address inequities contributing to high rates of maternal and infant mortality in rural western Kenya, the Academic Model Providing Access to Healthcare (AMPATH), in partnership with the Government of Kenya (GOK), launched Chamas for Change (Chamas) in 2012. This CHV-facilitated program offers pregnant women free health and microfinance education in a supportive group setting during the antenatal and postpartum period. Translated from Kiswahili as 'groups with purpose,' "chamas" have a longstanding presence in East Africa [20]. These groups are highly gendered institutions that women have relied on for centuries for social 
support and resource pooling [21]. Using this cultural script, our solution combines best practices from women's health and microfinance programs to create an integrated model that strives to not only improve health outcomes, but also interrupt cycles of poverty by empowering women to live financially-secure lives.

In this article, we report findings from a prospective matched cohort study in Busia County, Kenya. We evaluated the association between Chamas participation and facility-based delivery. We additionally explored the effect of program participation on promoting other $\mathrm{MNCH}$ behaviors, namely: attending at least four ANC visits, receiving a $\mathrm{CHV}$ home visit within $48 \mathrm{~h}$ postpartum, EBF to six months, using a modern FP method, using a long-term FP method, and vaccinating infants with OPV0 at birth. We hypothesized participating in Chamas would increase the odds of facility-based delivery and the practice of other positive $\mathrm{MNCH}$ behaviors compared to receiving the standard of care.

\section{Methods}

\section{Study setting and design}

We conducted our study in Bunyala, a rural sub-county in Busia, Western Province, Kenya. We selected Bunyala for two primary reasons: (1) the MMR and NMR are much higher than national estimates, and (2) the $\mathrm{MOH}$ demonstrated strong interest and support of AMPATH's programs and collaborations. Women and infants in Western Province suffer from the second highest maternal and neonatal mortality rates nationally [2, 22, 23]. In Busia County, the most recent estimate for infant mortality rate (IMR) is exceedingly high at 125.9 per 1000 live births [24]. In Bunyala, $\mathrm{MNCH}$ activities, including antenatal and postpartum care led by the GOK and supported by AMPATH, exist across 16 community units and $8 \mathrm{MOH}$ health facilities.

To evaluate our primary and secondary outcomes of interest, we used a prospective, matched-cohort study design. We compared outcomes between a cohort of Chamas participants recruited during their first ANC visits at public health facilities in Bunyala and controls receiving the standard of care identified through health facility registers, matched for age, parity, and prenatal care location. We followed both cohorts prospectively for one year and recorded outcome data 12 months following enrollment for all participants.

\section{Participant selection}

We used a facility-based recruitment strategy to enroll women to our intervention cohort. We invited all pregnant women attending their first ANC visit at an $\mathrm{MOH}-$ sponsored health facility in Bunyala between October-December 2012 to enroll in the Chamas program and to participate in this study (Fig. 1). We did not exclude women based on any sociodemographic or reproductive health factors including age, education-level, employment-status, marital status, parity, or prior history of facility delivery.

To recruit our control cohort, we retrospectively identified pregnant women who attended the same health facilities for their first ANC visits in the three months preceding Chamas enrollment (July-September 2012) from clinic registers. We matched controls based on three criteria: age, parity, and prenatal care location (health facility). We tasked CHVs with approaching eligible women at their homes, if they provided an address; we then enrolled women who were successfully located and agreed to participate (Fig. 1). Women in both cohorts provided baseline sociodemographic and reproductive health data at the time of enrollment and consented to complete a 12 month follow-up survey (612 months postpartum).

\section{Community health volunteers in Kenya}

Chamas leverages CHVs to deliver health and microfinance education in a safe and familiar setting. As delineated by Kenya's community health strategy, CHVs are members of the community, nominated from within, who are tasked with improving the community's health and well-being as well as linking individuals to primary health care services [25]. CHVs are considered part-time government volunteers and are supervised by Community Health Extension Workers (CHEWs), salaried frontline healthcare providers integrated within government health facilities [26]. CHV facilitators across both study arms were connected to eight health facilities, specifically: five dispensaries, two health centers, and one subcounty level hospital.

Nationally, the Kenyan government delineates a CHV's scope of work to include: monthly household visits within a defined catchment area of 20 households in rural areas and 100 households in urban areas [27]. During routine visits, $\mathrm{CHVs}$ collect basic health information, identify health problems, and refer individuals needing additional services to health facilities. All CHVs are required to complete a 10-day, $\mathrm{MOH}$-led basic training session prior to beginning work during which they are introduced to a broad array of health topics, including $\mathrm{MNCH}$. With regard to $\mathrm{MNCH}, \mathrm{CHVs}$ are provided with a handbook that covers basic information on caring for mothers during and after pregnancy, instructions on facilitating the creation of an individualized birth plan, and lists of specific health behaviors they are encouraged to promote (i.e. attend ANC, deliver in health facilities, adopt family planning) [27]. They are also expected to recognize danger signs during pregnancy as well as perform basic nutritional assessments, aid in growth monitoring, and recognize when infants require further evaluation for malnutrition. This basic training is often 


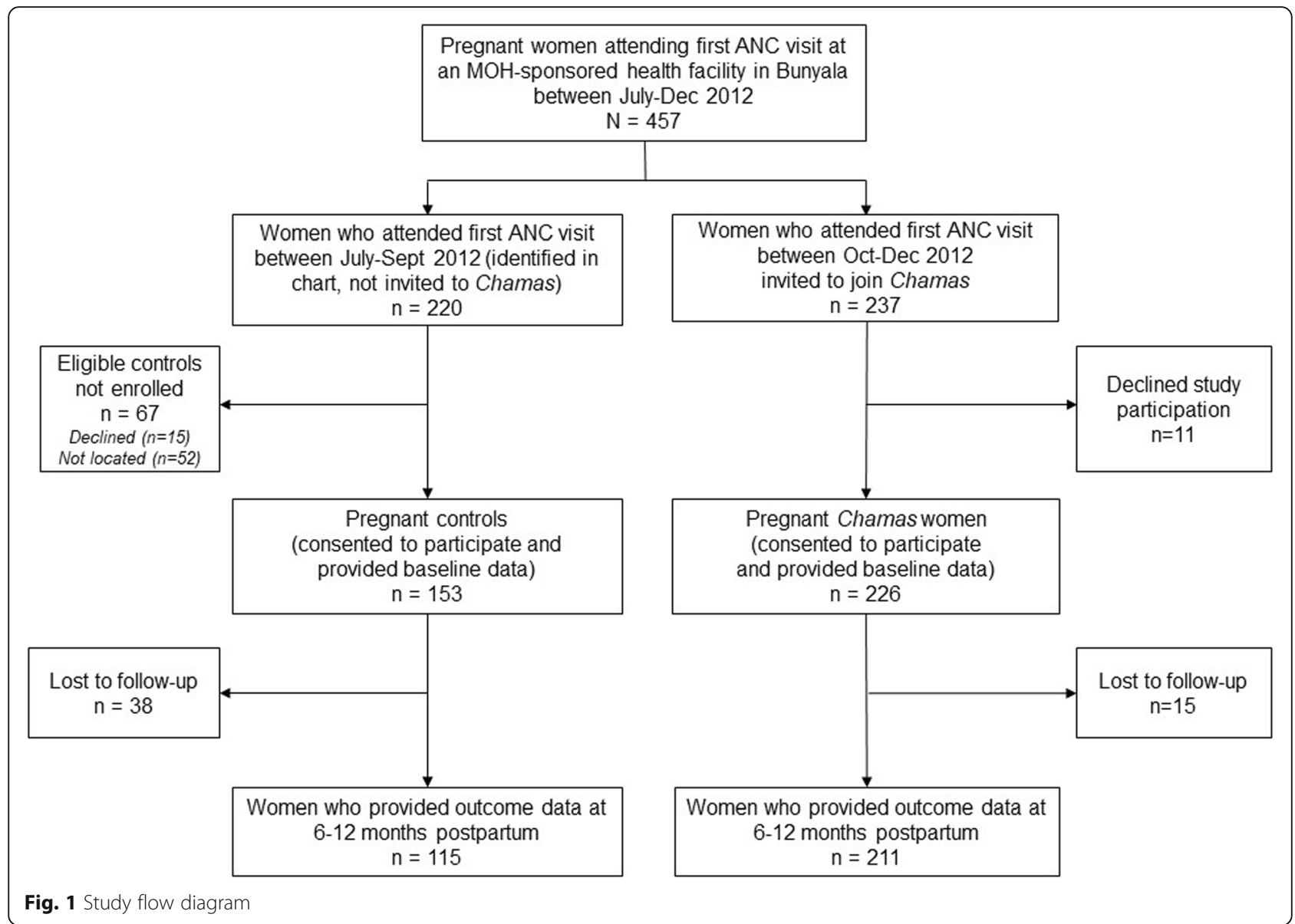

supplemented by technical training that aligns with local priorities; however, technical sessions are variable and often implemented by local governments or nongovernmental organizations [27].

In September 2012, we selected 32 GOK sponsored CHVs to participate in an additional four-day technical training session on Chamas, sponsored by AMPATH and the Busia County MOH. During these sessions, we trained attendees on how to deliver our evidence-based health curriculum using an illustrated flipchart, facilitate participatory group discussions, and equip program participants with basic microfinance literacy and skills. In addition to conducting didactic sessions, $\mathrm{CHVs}$ also received additional training on basic health interventions, such as taking vitals, assessing for hemorrhage and signs of infection at the 48-h postpartum home-visit, supporting mothers in exclusively breastfeeding, counselling participants on options for family planning, and adopting safe sleep practices. Throughout the year, CHVs attended regularly scheduled check-in meetings (at months 1-4, 6, 9, and 12) with AMPATH implementation leads to provide feedback, as well as receive additional mentorship and support.

\section{Intervention description}

Women attending Chamas convened twice per month for 12 months to attend a total of $24 \mathrm{CHV}$-facilitated group health education and microfinance sessions. Each group was typically comprised of 15-30 women and each session consisted of a 60 to 90 -min participatory lesson on one health (i.e. antenatal care, family planning) and one social (i.e. intimate partner violence, microfinance literacy) topic (Table 1). CHVs used an illustrated flip-chart with an accompanying discussion guide to facilitate sessions. Upon joining the program, women agreed to practice key $\mathrm{MNCH}$ behaviors, namely to: deliver in a health facility, attend at least four ANC visits, EBF to six months, receive a CHV home visit within 48 $\mathrm{h}$ of delivery, consider a long-term method of FP, ensure their infant received OPV0, and save money to finance health expenditures. Each group also delineated personal goals they wished to accomplish during the program.

Following lessons, members elected to participate in a table-banking program called "Group Integrated Savings for Health and Empowerment" (GISHE). GISHE is an adaptation of the Catholic Relief Services' Savings and Internal Lending model, which encourages a savings-led, group-based microfinance scheme [28]. We deemed 
Table 1 Health and Social Topics for Chamas for Change First-Year Curriculum ${ }^{a}$

\begin{tabular}{|c|c|c|}
\hline Lesson & Health Topic & Social Topic \\
\hline 1 & Importance of antenatal and postnatal care & Goals of the Chamas for Change program \\
\hline 2 & Physical exercise during pregnancy & Table banking (Saving and Loans) \\
\hline 3 & Anemia during pregnancy & National Hospital Insurance Fund (NHIF) \\
\hline 4 & Danger signs during pregnancy and after delivery & Nutrition during pregnancy \\
\hline 5 & Importance of facility delivery & $\begin{array}{l}\text { Involving male partners during pregnancy and while raising } \\
\text { children }\end{array}$ \\
\hline 6 & Preventing maternal-child transmission of infections & Supporting the birth of a child in your Chama \\
\hline 7 & Negative pregnancy outcomes (losing an infant) & Post-delivery welfare (up to 12 months of age) \\
\hline 8 & Complications during pregnancy and delivery (i.e. obstructed labor) & Creating a budget \\
\hline 9 & Postpartum depression & Setting routines for the infant: sleeping and eating \\
\hline 10 & Newborn danger signs ( $4 \mathrm{~h}$ to 2 weeks) & $\begin{array}{l}\text { Promoting a good relationship with your Mother-in-law and Sister- } \\
\text { in-law }\end{array}$ \\
\hline 11 & Exclusively breastfeeding for 6 months & Home hygiene \\
\hline 12 & Infant growth monitoring and under-5 immunizations & Disclosing HIV status to your family \\
\hline 13 & Kangaroo Care & Reducing stigma towards members in the community with HIV \\
\hline 14 & Back to sleep/co-sleeping & Cooking in clean air \\
\hline 15 & Family Planning: Coil/Uterine Copper Device & Farming and rearing livestock \\
\hline 16 & Family Planning: Jadelle, Implanon, Nexplanon & Clean water \\
\hline 17 & Family Planning: Male and Female Condoms & Intimate Partner Violence (IPV) \\
\hline 18 & Infant growth and development & Adolescent pregnancies \\
\hline 19 & Complementary feeding for infants & Importance of female education \\
\hline 20 & Basic first aid: choking and burns & Promoting a good relationship with your husband in the home \\
\hline 21 & $\begin{array}{l}\text { Pediatric diseases under surveillance: Measles, Polio, Pneumonia, and } \\
\text { Scabies }\end{array}$ & Mutual sexual satisfaction between a man and a woman \\
\hline 22 & Diarrheal Diseases & Preparing to take your child to school (preparing for pre-school) \\
\hline 23 & Cervical Cancer Screening: Overcoming fears and misconceptions & Group conflict resolution \\
\hline 24 & Malaria & Children with developmental delays \\
\hline
\end{tabular}

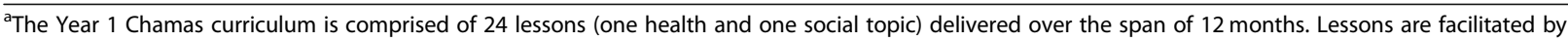
community health volunteers in a group-based setting using illustrated flip-charts and discussion guides

participation optional to avoid excluding women that could not afford to contribute the minimum $50 \mathrm{KSH}$ (0.50 USD) share per meeting. Members contributed up to ten times the amount of the minimal share at each Chamas session. The group provided loans that amounted to a multiple of the individual member's savings and returned a dividend payment based on interest accrued at the end of the year. Profits generated were distributed to the entire group in amounts proportional to individual shares contributed.

We designed Chamas in collaboration with the GOK and county-level $\mathrm{MOH}$ representatives to ensure support and investment from local community members. The Chamas curriculum was designed by a diverse group of stakeholders including AMPATH researchers, community members, and local $\mathrm{MOH}$ representatives. The curriculum was designed with the intent to highlight evidence-based recommendations by international authorities (i.e. WHO), bolster training provided through the current CHV handbook, and respond directly to the needs of and questions asked by the local community. We sought feedback throughout curriculum development through conducting focus group discussions with community representatives. This pilot study served as a debut for this curriculum.

Our control cohort received the current standard of care as delineated by the $\mathrm{MOH}$ (described under Community Health Volunteers in Kenya). In contrast to Chamas participants, they received monthly, individual CHV household visits, but did not participate in structured, evidence-based health education and microfinance sessions nor experience the group-based format offered by the program.

\section{Data collection and study variables}

We collected baseline and outcome data at two timepoints for all participants using paper-based, structured, data collection forms (Additional File 1). We tasked 
AMPATH research assistants trained in data entry with collecting data at both time-points. We recorded baseline data on sociodemographic and reproductive health information at enrollment and collected outcome data at 12 months follow-up (6-12 months postpartum). Interview location depended on the study time-point and cohort assignment. We collected baseline data on intervention participants at health facilities and on controls at participant homes on the day of enrollment. We collected all outcome data at participant homes. During both time-points, we made every effort to collect data individually and privately so as to minimize potential for response bias.

Our primary outcome was the odds of facility-based delivery. Our secondary $\mathrm{MNCH}$ outcomes included: the relative proportion of women who attended at least four ANC visits, received a CHV home-visit within $48 \mathrm{~h}$ postpartum, EBF to 6 months, adopted a modern FP method, and adopted a long-term or permanent FP method. We additionally assessed the relative proportion of infants that received OPV0 at birth across cohorts. Where possible, we extracted data from Maternal and Child Health $(\mathrm{MCH})$ booklets. If women did not have their $\mathrm{MCH}$ booklet available or if booklets missed data, we asked participants to self-report answers.

To assess the modifying effect of covariates we collected sociodemographic and reproductive health information, including: age, education level, employment status, marital status, parity, prior facility delivery (among those who previously delivered), and facility location of first ANC visit. Maternal age may worsen maternal and fetal outcomes, increasing the propensity of older women to seek care or establish contact with health facilities earlier in pregnancy [29]. Sociodemographic characteristics such as education level, employment status and marital status may impact the likelihood of facility delivery as these variables serve as proxies for socio-economic status. We defined "employment" as earning the national daily minimum wage of 450 Kenyan Shillings and allowed participants to select a categorical descriptor (i.e. housewife/unemployed, selfemployed, agricultural worker, other) [26]. Previous studies demonstrate women of lower socio-economic status or lower levels of education are less likely to deliver in facilities [30]. Further, reproductive health characteristics such as parity and prior facility delivery may positively or negatively impact a woman's likelihood of returning to facilities, based on experiences with the health system [31, 32]. Lastly, we collected first ANC visit facility location to address potential area-level variance on the likelihood of facility delivery.

Though not powered to detect significant differences, we assessed pregnancy-related morbidity and mortality outcomes as well as microfinance data using program monitoring logs recorded by CHVs. These outcomes specifically included: the gestational age (GA) at delivery, the incidence of miscarriage (defined as loss of fetus less than 28 weeks gestation) and stillbirth (defined as loss of fetus between 28 weeks and delivery), as well as the incidence of infant and maternal mortality. We restricted microfinance outcomes to the Chamas cohort and these included: the proportion participating in GISHE, individual loans received, group savings accumulated, and general categories of investment (i.e. school-fees, health expenditures, small businesses). CHVs reported these data monthly to trained research assistants, who electronically transcribed and uploaded outcomes to an encrypted database.

\section{Sample size determination}

To calculate our estimated sample size, we assumed 55\% of women who attended at least one ANC visit delivered in a health facility and an intra-class correlation coefficient of 0.34, which accounts for population-level variance due to area-level effects (i.e. contact and proximity to the health system and CHVs, clustering by health facility catchment area) [2, 33]. With these assumptions, we determined a 2:1 sample of 240 (156 Chamas and 84 Control) participants adequate to detect a $20 \%$ difference in the proportion of facility deliveries between intervention and control groups, with a type I error rate $(\alpha)$ of 0.05 and power of $85 \%$. We assumed a $10 \%$ loss to follow-up and established a final target sample size of 267 total participants.

\section{Data analysis}

We tabulated frequencies and calculated descriptive statistics comparing socio-demographic and reproductive health variables between Chamas participants and controls. For all bivariate analyses, we used student's T tests for continuous variables, Mann-Whitney U tests for continuous variables with non-normal distributions, twosample Z-score tests for proportions, and Chi-square tests for categorical variables.

Multivariable nested models were used to test the association between Chamas participation and facility delivery independently, with successive inclusion of covariates, namely: age, education level, employment status, marital status, parity, and prior facility delivery. We examined age as a continuous variable. We collapsed education level into a three-level categorical variable (none-some primary, completed primary, somecompleted secondary), and employment (unemployed vs. employed), marital status (single/separated/divorced vs. married), parity (nulliparous vs. multiparous), and prior facility delivery into dichotomous variables. We performed complete case analyses and excluded records 
with missing data on the primary outcome variable or covariates.

Random effects models, employing the same nestedinclusion technique described above, tested for significant area-level variance as determined by prenatal care location. We additionally ran an interaction model with ANC attendance (dichotomous variable, $<4$ visits vs. $\geq 4$ visits) and Chamas participation as we hypothesized mothers attending at least four ANC visits were more likely to deliver in a health facility than those who attended fewer than four visits [32]. We decided a priori to conduct an additional sensitivity analysis restricting our intervention sample solely to Chamas women who participated in GISHE to examine the impact of combined effect of health education and microfinance participation on $\mathrm{MNCH}$ intervention uptake. We conducted all statistical analyses using Stata version 13.1 (StataCorp, College Station, Texas) with $\alpha$ set to 0.05 .

\section{Ethical consideration and trial registration}

Our study received ethics approval from the Institutional Research Ethics Committee at Moi Teaching and Referral Hospital (IREC/2013/76), the Office of Research Administration at Indiana University (\#1306011628), and the Research Ethics Board at the University of Toronto (\# 2907). We obtained written informed consent from all participants prior to data collection. We retrospectively registered this study with ClinicalTrials.gov (NCT03188250). No substantial changes were made to the study design or outcomes following participant enrollment.

\section{Results}

Between October-December 2012, we identified and invited 237 women attending their first ANC visits to join Chamas; we simultaneously identified and attempted to contact 220 women who attended their first ANC visits in the three months preceding enrollment using clinic registers (Fig. 1). Most eligible women who were successfully contacted across both the control (153/168, $91.2 \%)$ and intervention $(226 / 237,95.4 \%)$ arms agreed to participate in this study. Loss to follow-up rates across the control and intervention arms at end-line assessment were 24.8 and $6.6 \%$, respectively. Results are solely reported for our final sample size of 326 women $(n=115$ control, $n=211$ intervention participants) who contributed outcome data 12 months following enrollment (between 6 and 12 months postpartum).

\section{Participant demographics}

Baseline sociodemographic and reproductive health characteristics by participant group are presented in Table 2. Overall, our cohort and intervention groups were well-matched with few significant differences.
Participants averaged 25.2 years of age. Most completed primary school, were married, and attended their first ANC visit at 22.1 weeks gestation. A significantly higher proportion of women in the control cohort were unemployed $(56.5 \%$ vs. $40.3 \%, p<0.05)$ and previously delivered a live-born infant $(100 \%$ vs. $87.7 \%, \mathrm{p}<0.05)$ than women in Chamas. Among women with a previous delivery, a significantly higher proportion of Chamas participants delivered in a health facility $(65.3 \%$ vs. $47.8 \%$, $p<0.05$ ); however, we reported missing data for nearly $20 \%$ of controls for this covariate.

\section{Practice of positive $\mathrm{MNCH}$ behaviors}

Results for the practice of positive $\mathrm{MNCH}$ behaviors by cohort are presented in Table 3. Compared to controls, a significantly higher proportion of Chamas participants delivered in a health facility $(84.4 \%$ vs. $50.4 \%, p<0.05)$, attended at least 4 ANC visits $(64.0 \%$ vs. $37.4 \%, \mathrm{p}<0.05)$, received a $\mathrm{CHV}$ home visit within $48 \mathrm{~h}$ postpartum ( $75.8 \%$ vs. $38.3 \%, \mathrm{p}<0.05)$, and exclusively breastfed to 6 months postpartum $(82.0 \%$ vs. $47.0 \%, \quad \mathrm{p}<0.05)$. Though not statistically significant, a higher proportion of Chamas participants adopted a modern method of contraception (58.2 vs. $55.6 \%, p=0.46)$ and among method adopters, a higher proportion chose a longacting or permanent FP method (66.7 vs. $62.5 \%, p=$ $0.58)$ as compared to controls. Lastly, a higher proportion of infants born to women participating in Chamas received the OPV0 immunization at birth $(91.9 \%$ vs. $85.2 \%, p=0.41$ ). Missing values comprised less than $10 \%$ of each cohort across all outcomes measured.

\section{Maternal and infant morbidity and mortality}

Women in Chamas delivered at a significantly older gestational age than controls $(39.4 \pm 2.7$ vs. $35.5 \pm 8.9, p<$ $0.001)$. Of note, $33 \%(n=38)$ of the control cohort missed data for this outcome, limiting interpretability of this result. Further, women in Chamas experienced a lower proportion of stillbirths $(0.9 \%$ vs. $5.2 \%)$, miscarriages $(5.2 \%$ vs. $7.8 \%)$, infant deaths $(2.8 \%$ vs. $3.4 \%)$, and maternal deaths $(0.9 \%$ vs. $1.7 \%)$ as compared to controls.

\section{Association between Chamas participation and health facility delivery}

Fully adjusted results from our multivariable analyses are presented in Table 4 . We excluded 19 participants (5.8\% of sample) from our analyses as they missed primary outcome data on facility delivery or on a covariate. Excluded participants did not substantially differ in sociodemographic or reproductive health characteristics from those included in our analysis. In our unadjusted model, Chamas participation was associated with over five times the odds of delivering at a health facility compared to controls (OR 5.49, 95\% CI 3.12-9.64, $p<0.001$ ). 
Table 2 Baseline sociodemographic and reproductive health characteristics by participant group for study population $(n=326)$

\begin{tabular}{|c|c|c|c|}
\hline \multirow[t]{2}{*}{ Variable } & Study Population $(n=326)$ & Chamas $(n=211)$ & Control $(n=115)$ \\
\hline & $M \pm S D$ or $\%(n)$ & $M \pm S D$ or $\%(n)$ & $M \pm S D$ or $\%(n)$ \\
\hline Age & $25.2 \pm 4.8$ & $25.2 \pm 5.0$ & $25.1 \pm 4.5$ \\
\hline \multicolumn{4}{|l|}{ Education level } \\
\hline None-some primary & $14.7(48)$ & $11.8(25)$ & $20.0(23)$ \\
\hline Completed Primary & $73.6(240)$ & 73.9 (156) & $73.0(84)$ \\
\hline Some secondary & $6.1(20)$ & $8.1(17)$ & $2.6(3)$ \\
\hline Completed secondary & $5.6(18)$ & $6.2(13)$ & $4.4(5)$ \\
\hline \multicolumn{4}{|l|}{ Employment ${ }^{*}$} \\
\hline Housewife (unemployed) & $46.0(150)$ & $40.3(85)$ & $56.5(65)$ \\
\hline Self-employed & $30.3(99)$ & $36.0(76)$ & $20.0(23)$ \\
\hline Agricultural worker & $16.3(53)$ & $18.0(38)$ & $13.0(15)$ \\
\hline Other & $7.4(24)$ & $5.7(12)$ & $10.5(12)$ \\
\hline \multicolumn{4}{|l|}{ Marital Status } \\
\hline Married & $86.8(283)$ & $85.3(180)$ & 89.6 (103) \\
\hline Single/Separated/Divorced & $13.2(43)$ & $14.7(31)$ & $10.4(12)$ \\
\hline \multicolumn{4}{|l|}{ Parity $^{*}$} \\
\hline Mean (SD) & $2.8 \pm 1.8$ & $2.5 \pm 1.8$ & $3.0 \pm 1.7$ \\
\hline Parous & $92.0(300)$ & $87.7(185)$ & $100.0(115)$ \\
\hline Nulliparous & $8.0(26)$ & $12.3(26)$ & $0.0(0)$ \\
\hline \multicolumn{4}{|l|}{ Prior facility delivery ${ }^{*}, \mathbf{a}, \mathbf{b}$} \\
\hline Yes & $58.7(176)$ & $65.3(121)$ & $47.8(55)$ \\
\hline No & $27.7(83)$ & $25.0(46)$ & $32.2(37)$ \\
\hline Gestational age at first ANC visit (weeks) & $22.1 \pm 8.5$ & $22.4 \pm 8.9$ & $21.8 \pm 8.0$ \\
\hline \multicolumn{4}{|l|}{ First ANC visit location ${ }^{\mathrm{b}}$} \\
\hline Port Victoria & $27.6(90)$ & $25.6(54)$ & $31.3(36)$ \\
\hline Budalangi & $8.3(27)$ & $7.6(16)$ & $9.6(11)$ \\
\hline Sirimba & $11.3(37)$ & $12.8(27)$ & $8.7(10)$ \\
\hline Sisenya & $12.9(42)$ & $12.8(27)$ & $13.0(15)$ \\
\hline Mukhobola & $13.2(43)$ & $11.9(25)$ & $15.7(18)$ \\
\hline Rukala & $15.6(51)$ & $16.1(34)$ & $14.8(17)$ \\
\hline Bulwani & $4.9(16)$ & $5.2(11)$ & $4.4(5)$ \\
\hline Osieko & $3.1(10)$ & $3.3(7)$ & $2.6(3)$ \\
\hline Other & $2.1(7)$ & $3.3(7)$ & $0.0(0)$ \\
\hline
\end{tabular}

"Significant $p<0.05$

${ }^{a}$ Among those with previous delivery (Chamas group $=185$; control group $\left.=115\right)$

${ }^{\mathrm{b}}$ Missing data: prior facility delivery $n=18$ (Chamas), $n=23$ (Control); first ANC location $\mathrm{n}=3$ (Chamas)

This effect was only slightly attenuated after controlling for age, education level, employment, marital status, parity, and prior facility delivery (OR 5.07, 95\% CI $2.74-$ 9.36, $\mathrm{p}<0.001)$. Following adjustment, prior facility delivery was the only significantly associated covariate; those with a prior facility delivery were roughly four times as likely as those without to deliver in a health facility (OR 4.31, 95\% CI 2.25-8.25, p < 0.001).

We used random effects modelling to determine whether significant area-level variance due to prenatal care location impacted the likelihood of facility delivery (Table 5). We grouped women according to the health facility they attended for their first antenatal visit; among our cohort of women, they sought care at eight different health facilities (five dispensaries, two health centers, and one sub-county level hospital) (Table 2). Our null model revealed a significant amount of area-level variance $\left(\sigma_{u}^{2}=0.30 \pm 0.24, p<0.05\right)$ in the odds of facility delivery. Following adjustment for covariates, the variance remained statistically significant $\left(\sigma_{\mathrm{u}}{ }^{2}=0.44 \pm 0.39\right.$, 
Table 3 Practice of maternal, newborn and child health behaviors by participant group for study population $(n=326)$

\begin{tabular}{|c|c|c|c|}
\hline \multirow[t]{2}{*}{ Health Behavior } & Study Population $(n=326)$ & Chamas $(n=211)$ & Control $(n=115)$ \\
\hline & $\mathrm{M} \pm \mathrm{SD}$ or $\%(\mathrm{n})$ & $M \pm S D$ or $\%(n)$ & $M \pm S D$ or $\%(n)$ \\
\hline \multicolumn{4}{|c|}{ Delivered in a facility with skilled birth attendant ${ }^{*, b}$} \\
\hline Yes & $72.4(236)$ & $84.4(178)$ & $50.4(58)$ \\
\hline No & $22.7(74)$ & $12.8(27)$ & $40.9(47)$ \\
\hline \multicolumn{4}{|c|}{ Attended $\geq 4$ ANC visits ${ }^{*}, \mathrm{~b}$} \\
\hline Yes & $54.6(178)$ & $64.0(135)$ & $37.4(43)$ \\
\hline No & $43.9(143)$ & $33.7(71)$ & $62.6(72)$ \\
\hline \multicolumn{4}{|c|}{ Received CHV 48-h postpartum home visit ${ }^{*}, \mathrm{~b}$} \\
\hline Yes & $62.6(204)$ & $75.8(160)$ & $38.3(44)$ \\
\hline No & $32.5(106)$ & $19.9(42)$ & $55.7(64)$ \\
\hline \multicolumn{4}{|c|}{ Exclusively breastfed $\geq 6$ months ${ }^{*}, \mathrm{~b}$} \\
\hline Yes & $69.6(227)$ & $82.0(173)$ & $47.0(54)$ \\
\hline No & $22.7(74)$ & $11.9(25)$ & $42.6(49)$ \\
\hline \multicolumn{4}{|c|}{ Adopted any modern family planning method or permanent method (oral contraceptives, injections, IUD, implant, tubal ligation) } \\
\hline Yes & $57.4(187)$ & $58.2(123)$ & $55.6(64)$ \\
\hline No & $41.7(136)$ & $40.7(86)$ & $44.3(51)$ \\
\hline \multicolumn{4}{|c|}{ Adopted a long-term or permanent method of family planning (IUD, implant, tubal ligation) ${ }^{a}$} \\
\hline Yes & $65.0(122)$ & $66.7(82)$ & $62.5(40)$ \\
\hline No & $34.8(65)$ & $33.3(41)$ & $47.1(24)$ \\
\hline \multicolumn{4}{|c|}{ Infant received OPV0 immunization ${ }^{\mathrm{b}}$} \\
\hline Yes & $89.5(292)$ & $91.9(194)$ & $85.2(98)$ \\
\hline No & $3.4(11)$ & $2.8(6)$ & $4.4(5)$ \\
\hline
\end{tabular}

$\mathrm{p}<0.05$ ); however, the association between Chamas participation and adjusted odds of delivering in a health facility was materially unchanged (OR 5.60, 95\% CI 2.91-10.80, $p<0.001)$.

Finally, we tested for interaction between ANC attendance and Chamas participation with a likelihood ratio test and did not find an interaction effect based on an a priori significance level of 0.05 (analyses not shown).

\section{Effect of microfinance participation}

Among all women participating in Chamas, $71.8 \%(n=$ 152) also participated in GISHE. A significantly higher proportion of women participating in GISHE completed at least some secondary school $(18.9 \%$ vs. $3.4 \%, p<0.05)$ and were employed $(63.5 \%$ vs. $48.3 \%, \mathrm{p}<0.05)$ than those who chose not to participate. On average, six group members received loans per meeting, varying from 200 to $2000 \mathrm{KSH}$ (2-22 USD). Women primarily used loans to pay for school fees, business start-up costs and health service-related fees. All 16 Chamas groups generated adequate funds to repay group start-up costs of $5000 \mathrm{KSH}$ (50 USD). There were no statistically significant differences in either the primary (facility delivery) or secondary outcomes when we compared GISHE participants to those not participating within the Chamas cohort.

We conducted an additional sensitivity analysis restricting our intervention sample solely to Chamas women who participated in GISHE $(n=152)$ to examine the impact of both health education and microfinance participation on $\mathrm{MNCH}$ intervention uptake. Results generated by this model were materially unchanged from those generated by our multivariable models (analyses not shown).

\section{Discussion}

Major findings

In this study, we evaluated the association between Chamas participation and facility-based delivery in rural western Kenya. We additionally explored the effect of program participation on promoting other positive $\mathrm{MNCH}$ behaviors. We affirmed our hypothesis by demonstrating Chamas participants had a significantly higher odds of achieving a facility-based delivery as 
Table 4 Multivariable logistic regression model of association between Chamas participation and facility delivery adjusted for sociodemographic and reproductive health covariates $(n=307)^{\mathrm{a}}$

\begin{tabular}{|c|c|c|c|}
\hline \multirow[t]{2}{*}{ Variable } & \multicolumn{3}{|c|}{ Facility delivery with skilled birth attendant } \\
\hline & $\mathrm{OR}$ & $(95 \% \mathrm{Cl})$ & $p$-value \\
\hline \multicolumn{4}{|l|}{ Chamas participation } \\
\hline Did not participate in Chamas & - & - & - \\
\hline Participated (unadjusted) & 5.49 & $(3.12,9.64)$ & $<0.001$ \\
\hline Participated (adjusted) & 5.07 & $(2.74,9.36)$ & $<0.001$ \\
\hline Age (years) & 1.00 & $(0.93,1.08)$ & 0.92 \\
\hline \multicolumn{4}{|l|}{ Education level } \\
\hline None-some primary & - & - & - \\
\hline Completed primary & 1.22 & $(0.56,2.66)$ & 0.63 \\
\hline Some-completed secondary & 3.24 & $(0.74,14.17)$ & 0.12 \\
\hline \multicolumn{4}{|l|}{ Employment } \\
\hline Housewife (unemployed) & - & - & - \\
\hline Self-employed/Agricultural Worker/Other & 1.38 & $(0.74,2.55)$ & 0.31 \\
\hline \multicolumn{4}{|l|}{ Marital Status } \\
\hline Single/Separated/Divorced & - & - & - \\
\hline Married & 1.56 & $(0.52,4.63)$ & 0.43 \\
\hline \multicolumn{4}{|l|}{ Parity } \\
\hline Primiparous & - & - & - \\
\hline Multiparous & 1.10 & $(0.18,6.89)$ & 0.92 \\
\hline \multicolumn{4}{|l|}{ Prior facility delivery } \\
\hline No & - & - & - \\
\hline Yes & 4.31 & $(2.25,8.25)$ & $<0.001$ \\
\hline
\end{tabular}

${ }^{a}$ Complete cases only; $n=19$ participants missing data on primary outcome or covariate

compared to women receiving the standard of care. Additionally, larger proportions of Chamas participants attended at least four ANC visits, breastfed exclusively to six months, and received a 48 -h postpartum $\mathrm{CHV}$ home-visit. Though not statistically significant, a larger proportion of Chamas participants adopted a long-term or permanent FP method and immunized infants with OPV0 compared to controls. Taken together, these results suggest Chamas may offer a promising strategy to promote positive MNCH behaviors needed to achieve SDG targets by 2030.

Our random effect models revealed significant arealevel variance based on location of prenatal care and likelihood of facility delivery. Of interest, the variance remained statistically significant after controlling for covariates. This finding suggests there may be unobserved compositional effects within Chamas groups - or contextual effects between them - that explain some of the remaining variance in our primary outcome. The specific characteristics of our program that promote health care access are out of scope for the present study; however, future work may elucidate the causal pathways through which Chamas involvement influences uptake of $\mathrm{MNCH}$ services.
Further, we examined the combined effect of health education and microfinance participation on achieving $\mathrm{MNCH}$ outcomes. Recent literature suggests integrating microfinance schemes within women's health education or service delivery programs may enhance health outcomes [34, 35]. Though our sensitivity analyses revealed no significant difference in results based on microfinance participation, non-GISHE participants comprised less than half of the intervention cohort. Additionally, we did not assess participation in microfinance activities apart from GISHE across cohorts though crude estimates suggest a substantial portion of the population (nearly $30 \%$ in some rural western Kenyan counties) is involved in table-banking [36, 37]. It is possible participation in other microfinance schemes may nullify the effect of GISHE participation; however, additional research is needed to clarify this association. We also plan to clarify use of GISHE funds and to investigate the impact of investing in health-related expenditures.

\section{Strengths and limitations}

Our study has several notable strengths. We used a prospective, matched-cohort design to ensure reasonable 
Table 5 Nested random effects models of association between Chamas participation and facility delivery controlling for prenatal care location $(n=307)^{a}$

\begin{tabular}{|c|c|c|c|}
\hline \multirow[t]{2}{*}{ Model variance estimates } & \multicolumn{3}{|c|}{ Random Effects Model } \\
\hline & Null & Unadjusted & Adjusted \\
\hline$\overline{\sigma_{u}^{2}(S E)}$ & $0.30(0.24)$ & $0.51(0.40)$ & $0.44(0.39)$ \\
\hline$\rho(S E)$ & $0.08(0.06)$ & $0.14(0.09)$ & $0.12(0.09)$ \\
\hline$p$-value ${ }^{\square}$ & 0.01 & $<0.01$ & 0.01 \\
\hline-2 log likelihood & 330.23 & 291.10 & 267.40 \\
\hline Covariates & OR $(95 \% \mathrm{Cl})$ & OR $(95 \% \mathrm{Cl})$ & OR $(95 \% \mathrm{Cl})$ \\
\hline \multicolumn{4}{|l|}{ Chamas participation } \\
\hline Did not participate in Chamas & N/A & - & - \\
\hline Participated & N/A & $6.40(3.44,11.76)$ & $5.60(2.91,10.80)^{+t}$ \\
\hline Age (years) & N/A & $\mathrm{N} / \mathrm{A}$ & $1.00(0.92,1.08)$ \\
\hline \multicolumn{4}{|l|}{ Education level } \\
\hline None-some primary & $\mathrm{N} / \mathrm{A}$ & N/A & - \\
\hline Completed primary & N/A & N/A & $1.22(0.54,2.74)$ \\
\hline Some-completed secondary & N/A & N/A & $3.28(0.73,14.75)$ \\
\hline \multicolumn{4}{|l|}{ Employment } \\
\hline Housewife (unemployed) & N/A & $\mathrm{N} / \mathrm{A}$ & - \\
\hline Self-employed/Agricultural Worker/Other & N/A & N/A & $1.47(0.76,2.85)$ \\
\hline \multicolumn{4}{|l|}{ Marital Status } \\
\hline Single/Separated/Divorced & N/A & N/A & - \\
\hline Married & N/A & N/A & $1.35(0.44,4.15)$ \\
\hline \multicolumn{4}{|l|}{ Parity } \\
\hline Primiparous & N/A & N/A & - \\
\hline Multiparous & N/A & $\mathrm{N} / \mathrm{A}$ & $1.03(0.15,6.95)$ \\
\hline \multicolumn{4}{|l|}{ Prior facility delivery } \\
\hline No & N/A & N/A & - \\
\hline Yes & N/A & N/A & $4.16(2.09,8.27)^{+\dagger}$ \\
\hline
\end{tabular}

${ }^{a}$ Complete cases only; $n=19$ participants missing data on primary outcome or covariate

Likelihood ratio test, $\rho=0$

${ }^{+\dagger}$ Significant $p<0.001$

comparisons between Chamas participants and controls. Our cohorts were relatively well-matched, with adequate sample sizes to detect significant differences in our primary and secondary outcomes. We designed the Chamas program in collaboration with GOK and county-level $\mathrm{MOH}$ representatives, which offers confidence in longterm support and investment from local stakeholders. Further, our study aligns with current task-sharing recommendations by providing evidence to support the mobilization of CHVs to address unmet needs of pregnant and postpartum women [38]. Chamas also builds upon preceding group-based programs to enhance $\mathrm{MNCH}$ in resource-limited settings. In resource-limited settings, CHV-based efforts to promote health education through women's groups have demonstrated substantial promise in improving $\mathrm{MNCH}$ outcomes [39-44]. Chamas integrates these strategies to provide tailored programming that addresses needs of rural Kenyan women and infants. Collectively, these findings underscore a need for additional work to clarify whether there may be a synergistic effect in combining $\mathrm{MNCH}$ education and microfinance participation on population-level health and financial outcomes [39-44]. Moreover, regional and national efforts to address $\mathrm{MNCH}$ are increasing in Kenya as evidenced by publicly-funded insurance initiatives such as Linda Mama and the National Hospital Insurance Fund [45]. These services strive to ensure pregnant women and infants have access to quality and affordable health services by promoting universal health coverage. To clarify associations between Chamas participation and concurrent initiatives aimed at improving $\mathrm{MNCH}$ outcomes, we plan to assess and control for additional demographics such as health insurance enrollment in future studies. 
There are several noteworthy limitations of our study. First, though we were able to detect significant differences in our primary health-related outcomes of interest, we did not adequately power our study to determine the effect of Chamas participation on maternal and infant morbidity and mortality. We plan to examine these outcomes more thoughtfully in future studies with more reliable measures to assess morbidity (i.e. infant birthweight). Second, though we intended to conduct end-line assessments with all study participants around 6-12 months postpartum, we assessed most participants closer to 9-15 months postpartum due to logistical constraints. This time-lag may have increased risk for recall bias, particularly when objective data were not available from $\mathrm{MCH}$ Booklets. Third, our recruitment model introduced significant challenges that likely limited our control cohort size and introduced selection bias. By recruiting women from ANC facilities, we may have inadvertently excluded the most vulnerable women in the community who experience barriers to accessing care. Future strategies that combine both facility and community-based recruitment methods should be explored. Fourth, we experienced retention-related challenges as many families moved or did not supply reliable addresses; as such, we experienced high lost to follow-up rates particularly among our control cohort. Instituting a more reliable tracking method will be essential to increase cohort size and limit loss-to-follow-up in future studies. Fifth, though we sought to decrease the risk of response bias by collecting participant data privately, we speculate some women over-reported positive health behavior adherence due to pressure associated with social desirability. Sixth, our paper-based assessments resulted in substantial missing data on both demographic and outcome indicators. As such, we were unable to include all participants in our analysis of our primary outcome. We intend to use digital-based data collection methods to improve data quality, expedite collection, and decrease risk of missing data in future studies. Lastly, we did not record individual-level program attendance, which limited our ability to evaluate an associated intervention dose-response effect. We plan to further investigate this question in larger cohort studies by recording individual-level attendance data for all Chamas participants.

\section{Implications for practice}

Our findings demonstrated participation in a groupbased health education and microfinance program during the antenatal and postpartum period was associated with higher odds of facility-based delivery compared to the standard of care. Program participation also promoted the practice of other positive $\mathrm{MNCH}$ behaviors. Local $\mathrm{MOH}$ representatives and policymakers should consider Chamas when seeking alternative strategies to promote positive $\mathrm{MNCH}$ behaviors in resource-limited settings.

Though these results highlight Chamas' potential, it is important to acknowledge quality and availability of services may impair translated improvement in health outcomes. The intent to deliver in a health facility, for instance, may be compromised if trained providers are in short-supply or inadequately prepared to deliver lifesaving interventions. Participant-driven behaviors, such as exclusively breastfeeding, may conversely yield more consistent outcomes as these behaviors are less dependent on external services. By highlighting this distinction, we underscore the importance of not only promoting positive behaviors but also bolstering the quality of services provided to those who seek them.

Currently, the Chamas program is gradually transitioning leadership to the Busia County $\mathrm{MOH}$, whose representatives have supported the program's growth and sustainability. Now in its sixth year, Chamas has worked with over 1100 mother-infant dyads to promote positive $\mathrm{MNCH}$ behaviors across the county. In the near future, we hope to clarify the program's impact on $\mathrm{MNCH}$ outcomes on a population-level by pursuing a cluster randomized controlled trial.

\section{Conclusions}

In summary, Chamas participation during pregnancy and postpartum was associated with a five-fold increase in the odds of facility-based delivery compared to receiving the standard of care in rural western Kenya. Larger proportions of program participants also practiced other positive $\mathrm{MNCH}$ behaviors. This program demonstrates potential to achieve population-level $\mathrm{MNCH}$ benefits; however, a larger study is needed to validate this observed effect.

\section{Supplementary information}

Supplementary information accompanies this paper at https://doi.org/10. 1186/s12884-020-02978-W.

Additional file 1. Data collection forms and questionnaire guides for intervention and control cohorts.

\section{Abbreviations}

AMPATH: Academic Model Providing Access to Healthcare; ANC: Antenatal Care; Chamas: Chamas for Change Program; CHEW: Community Health Extension Worker; CHV: Community Health Volunteer; EBF: Exclusively Breastfeed; FP: Family Planning; GA: Gestational Age; GISHE: Group Integrated Savings for Health and Empowerment; GOK: Government of Kenya; IMR: Infant Mortality Rate; MCH: Maternal and Child Health; MMR: Maternal Mortality Ratio; MNCH: Maternal, Newborn, and Child Health; $\mathrm{MOH}$ : Ministry of Health; NMR: Neonatal Mortality Rate; OPVO: Oral Polio Vaccine 0; SBA: Skilled Birth Attendant; SDG: Sustainable Development Goal; WHO: World Health Organization 


\section{Acknowledgements}

We thank the Busia County $\mathrm{MOH}$ officials, health providers, CHVs, and Community Health Extension Workers who informed the design and implementation of the Chamas for Change program. We thank the following colleagues for their invaluable mentorship: Benjamin Chemwolo, Louis Fazen, Wendy Prudhomme O'Meara, Diana Menya, and Michael Scanlon. We additionally thank Carolyne Kipkoech, Kelsey Ragan, Tirajeh Saadatzadeh, and Mungai for their support in data collection. Lastly, we thank our program participants without whom this study would not be possible.

\section{Authors' contributions}

$A C D, L J R, J J S$, and DCC made substantial contributions to the conception and design of this work. JEl, SC, MAO, and CBO played critical roles in the design of data collection instruments and data acquisition process. JWS, LYM, LJR, and CBO led data analysis and interpretation. ACD, LYM, JWS, DCC, and JJS drafted the first iterations of the manuscript. LYM, LJR and ACD substantially revised the article. LYM compiled final author edits to the manuscript, supporting materials, and submitted final draft to the journal. All authors approved the submitted version of this article and agreed both to be personally accountable for the author's own contributions and to ensure that questions related to the accuracy or integrity of any part of the work (even ones in which the author was not personally involved), are appropriately investigated, resolved, and the resolution documented in the literature.

\section{Funding}

We thank Saving Lives at Birth (Grant No. \#0033-03-01-01-01) and USAID PEPFAR (Grant No. 623-A-00-08-00003-00 for their generous support of this work. These funding bodies had no role in the design of the study or in the collection, analysis, interpretation of data, or writing of this manuscript.

\section{Availability of data and materials}

The datasets used and/or analyzed during the current study are available from the corresponding author on reasonable request.

\section{Ethics approval and consent to participate}

Our study received ethics approval from the Institutional Research Ethics Committee at Moi Teaching and Referral Hospital (IREC/2013/76), the Office of Research Administration at Indiana University (\#1306011628), and the Research Ethics Board at the University of Toronto (\# 2907).

\section{Consent for publication}

Not applicable.

\section{Competing interests}

The authors declare that they have no competing interests.

\section{Author details}

${ }^{1}$ Academic Model Providing Access to Healthcare (AMPATH), P.O. Box 4606, Eldoret 30100, Kenya. ${ }^{2}$ Department of Medicine, Department of Pediatrics, Massachusetts General Hospital, Boston, MA, USA. ${ }^{3}$ Moi University School of Medicine, College of Health Sciences, Eldoret, Kenya. ${ }^{4}$ Division of Maternal-Fetal Medicine, Department of Obstetrics and Gynaecology, Mount Sinai Hospital, University of Toronto, Toronto, Ontario, Canada. ${ }^{5}$ LVCT Health, Nairobi, Kenya. ${ }^{6}$ Kenya Red Cross, Bomet, Kenya. ${ }^{7}$ Dalla Lana School of Public Health, University of Toronto, Toronto, Ontario, Canada. ${ }^{8}$ Department of Medicine, Indiana University, Indianapolis, IN, USA. ${ }^{9}$ Department of Obstetrics and Gynaecology, University of British Columbia, Vancouver, British Columbia, Canada.

Received: 24 June 2019 Accepted: 30 April 2020

Published online: 12 May 2020

\section{References}

1. United Nations. Sustainable Development Goal 3: Ensure healthy lives and promote well-being for all at all ages. United Nations. https:// sustainabledevelopment.un.org/sdg3. Published 2019. Accessed May 28, 2019.

2. Kenya National Bureau of Statistics, et al. 2014 Kenya Demographic and Health Survey (KDHS). Nairobi: DHS; 2015.
3. World Health Organization. Consensus Statement: Targets and Strategies for Ending Preventable Maternal Mortality. Geneva; 2014.

4. Bhutta ZA, Ahmed T, Black RE, et al. What works? Interventions for maternal and child undernutrition and survival. Lancet. 2008;371(9610):417-40.

5. World Health Organization. Making pregnancy safer: the critical role of the skilled attendant. Geneva: WHO Department of Reproductive Health and Research; 2004.

6. World Health Organization. WHO recommendations on antenatal care for a positive pregnancy experience. Geneva: World Health Organization; 2016.

7. Kenya Ministry of Health. Focused Antenatal Care. Nairobi: Ministry of Health; 2014.

8. Bakibinga P, Kamande E, Kisia L, Omuya M. Report of the 2017 End-line Survey for the Community Health Volunteers' Decision Support System Project. Nairobi: African Population and Health Research Center; 2018.

9. Kenya Ministry of Health. Monitoring and Evaluation Plan for Community Health Services (2014-2018). Nairobi: Government of Kenya; 2014.

10. World Health Organization. Exclusive breastfeeding for optimal growth, development and health of infants. World Health Organization. https:// www.who.int/elena/titles/exclusive_breastfeeding/en/. Published 2019. Accessed May 28, 2019.

11. Temmerman M, Khosla R, Bhutta ZA, Bustreo F. Towards a new global strategy for Women's, Children's and Adolescents' Health. BMJ. 2015;351: h4414.

12. Cleland J, Conde-Agudelo A, Peterson H, Ross J, Tsui A. Contraception and health. Lancet. 2012;380(9837):149-56.

13. World Health Organization. Family Planning/Contraception. World Health Organization. https:/www.who.int/news-room/fact-sheets/detail/familyplanning-contraception. Published 2018. Accessed June 3, 2019.

14. Conde-Agudelo A, Rosas-Bermudez A, Kafury-Goeta AC. Birth spacing and risk of adverse perinatal outcomes: a meta-analysis. Jama. 2006;295(15): 1809-23.

15. Lund N, Andersen A, Hansen AS, et al. The effect of Oral polio vaccine at birth on infant mortality: a randomized trial. Clin Infect Dis. 2015;61(10): 1504-11.

16. Black RE, Allen LH, Bhutta ZA, et al. Maternal and child undernutrition: global and regional exposures and health consequences. Lancet. 2008; 371(9608):243-60,

17. Kitui J, Lewis S, Davey G. Factors influencing place of delivery for women in Kenya: an analysis of the Kenya demographic and health survey, 2008/2009. BMC Pregnancy Childbirth. 2013;13:40.

18. The World Bank. Financial Inclusion Overview. http://www.worldbank.org/ en/topic/financialinclusion/overview\#1. Published 2019. Accessed June 17, 2019.

19. Financial Sector Deepening (FSD) Kenya. 2016 FinAccess Household Survey: FinAccess; 2016

20. Karega MR. Women's groups: from welfare to small-scale business in Kenya. Small Enterprise Dev. 1996;7(1):31-41.

21. Kitetu C. Organizational networks of Kenyan female migrants in England: the humble Chama now operating at higher international levels. London: United Kingdom; 2013.

22. Bennett C, Wamalwa D. Report on the midterm evaluation of the Busia child survival project (BCSP). Busia District, Kenya: African Medical and Research Foundation; 2008.

23. van Eijk AM, Adazu K, Ofware P, Vulule J, Hamel M, Slutsker L. Causes of deaths using verbal autopsy among adolescents and adults in rural western Kenya. Trop Med Int. 2008;13(10):1314-24.

24. Knoema. Busia - Infant Mortality Rate. https://knoema.com/atlas/Kenya/ Busia/Infant-Mortality-Rate. Published 1999. Accessed June 3, 2019.

25. Republic of Kenya Ministry of Health. Strategy for Community Health (20142019) Transforming health: Accelerating the attainment of health goals. Nairobi: Ministry of Health; 2019.

26. Government of Kenya. Strategic Plan of Kenya: Taking the Kenya Essential Package for Health to the Community. Nairobi: Ministry of Health; 2006. p. 2006.

27. Ministry of Health Division of Community Health Services. Community Health Volunteers (CHVs): Basic Modules Handbook. Nairobi: USAID; 2013.

28. Catholic Relief Services. Savings Led Microfinance. https://www.crs.org/ourwork-overseas/program-areas/savings-led-microfinance. Published 2019. Accessed May 30, 2019.

29. Dunlop CL, Benova L, Campbell O. Effect of maternal age on facility-based delivery: analysis of first-order births in 34 countries of sub-Saharan Africa using demographic and health survey data. BMJ Open. 2018;8(4):e020231. 
30. Nyongesa C, Xu X, Hall JJ, Macharia WM, Yego F, Hall B. Factors influencing choice of skilled birth attendance at ANC: evidence from the Kenya demographic health survey. BMC Pregnancy Childbirth. 2018;18(1):88.

31. Gitonga $E$, Muiruri F. Determinants of health facility delivery among women in Tharaka Nithi county, Kenya. Pan Afr Med J. 2016;25(Suppl 2):9.

32. Boah M, Mahama AB, Ayamga EA. They receive antenatal care in health facilities, yet do not deliver there: predictors of health facility delivery by women in rural Ghana. BMC Pregnancy Childbirth. 2018;18(1):125.

33. Kruk ME, Rockers PC, Mbaruku G, Paczkowski MM, Galea S. Community and health system factors associated with facility delivery in rural Tanzania: a multilevel analysis. Health Policy. 2010;97(2-3):209-16.

34. Isangula KG. Improving women and Family's health through integrated microfinance, health education and promotion in rural areas. J Sustainable Dev. 2012;5(5):1-14.

35. Lorenzetti LMJ, Leatherman S, Flax VL. Evaluating the effect of integrated microfinance and health interventions: an updated review of the evidence. Health Policy Plan. 2017;32(5):732-56.

36. Gikandi JW, Bloor C. Adoption and effectiveness of electronic banking in Kenya. Electron Commer Res Appl. 2010;9(4):277-82.

37. Academic Model Providing Access to Healthcare. Turbo Community Baseline; 2018. p. 1-7.

38. Rosato M, Laverack G, Grabman LH, et al. Community participation: lessons for maternal, newborn, and child health. Lancet. 2008;372(9642):962-71.

39. Lewycka S, Mwansambo C, Rosato M, et al. Effect of women's groups and volunteer peer counselling on rates of mortality, morbidity, and health behaviours in mothers and children in rural Malawi (MaiMwana): a factorial, cluster-randomised controlled trial. Lancet. 2013;381(9879):1721-35.

40. Manandhar DS, Osrin D, Shrestha BP, et al. Effect of a participatory intervention with women's groups on birth outcomes in Nepal: clusterrandomised controlled trial. Lancet. 2004;364(9438):970-9.

41. Tripathy P, Nair N, Barnett $\mathrm{S}$, et al. Effect of a participatory intervention with women's groups on birth outcomes and maternal depression in Jharkhand and Orissa, India: a cluster-randomised controlled trial. Lancet. 2010; 375(9721):1182-92.

42. Tripathy P, Nair N, Sinha R, et al. Effect of participatory women's groups facilitated by accredited social health activists on birth outcomes in rural eastern India: a cluster-randomised controlled trial. Lancet Glob Health. 2016;4(2):e1 19-28.

43. Azad K, Barnett S, Banerjee B, et al. Effect of scaling up women's groups on birth outcomes in three rural districts in Bangladesh: a cluster-randomised controlled trial. Lancet. 2010;375(9721):1193-202.

44. Fottrell E, Azad K, Kuddus A, et al. The effect of increased coverage of participatory women's groups on neonatal mortality in Bangladesh: a cluster randomized trial. JAMA Pediatr. 2013;167(9):816-25.

45. National Health Insurance Fund. NHIF: National Hospital Insurance Fund Linda Mama Services. NHIF. http://www.nhif.or.ke/healthinsurance/ lindamamaServices. Published 2020. Accessed February 2, 2020.

\section{Publisher's Note}

Springer Nature remains neutral with regard to jurisdictional claims in published maps and institutional affiliations.

Ready to submit your research? Choose BMC and benefit from:

- fast, convenient online submission

- thorough peer review by experienced researchers in your field

- rapid publication on acceptance

- support for research data, including large and complex data types

- gold Open Access which fosters wider collaboration and increased citations

- maximum visibility for your research: over $100 \mathrm{M}$ website views per year

At $\mathrm{BMC}$, research is always in progress.

Learn more biomedcentral.com/submissions 